\title{
The Use of Biochemical Markers, Serotype and Fimbriation in the Detection of Escherichia coli Clones
}

\author{
By ANNELIE BRAUNER, ${ }^{1}$ * JEAN-MARC BOEUFGRAS, ${ }^{2}$ \\ STEFAN H. JACOBSON, ${ }^{3}$ BERTIL KAIJSER, ${ }^{4}$ GUNILLA KÄLLENIUS, ${ }^{5}$ \\ STEFAN B. SVENSON ${ }^{5}$ AND BENGT WRETLIND 6 \\ ${ }^{1}$ Department of Clinical Microbiology, Karolinska Hospital, S-104 01 Stockholm, Sweden \\ 2 Laboratoire de Recherche, API, La Balme-les Grottes, France \\ ${ }^{3}$ Department of Medicine, Division of Nephrology, Karolinska Hospital, S-104 01 Stockholm, \\ Sweden \\ ${ }^{4}$ Department of Clinical Bacteriology, Institute of Clinical Bacteriology, Immunology and \\ Virology, University of Göteborg, S-413 46 Göteborg. Sweden \\ ${ }^{5}$ Department of Bacteriology, National Bacteriological Laboratory, S-105 21 Stockholm, Sweden \\ ${ }^{6}$ Department of Clinical Bacteriology, Danderyd Hospital, S-182 88 Danderyd, Stockholm, \\ Sweden
}

(Received 18 February 1987; revised 15 May 1987)

\begin{abstract}
Biochemical reactions, $\mathrm{O}$ and $\mathrm{K}$ serotypes and presence of $\mathrm{P}$-fimbriae were analysed in 116 Escherichia coli strains isolated in blood cultures from patients with bacteraemia and in 99 faecal strains isolated from healthy individuals. By using biochemical typing, the strains could be grouped into six main clusters with similarity index $<0.8$ (Gower, 1971) and altogether 16 subclusters with similarity index $0 \cdot 82-0 \cdot 89$. The most discriminating tests between the clusters were fermentation of D-tagatose, saccharose, salicin and sorbose. No single biochemical property could differentiate bacteraemic isolates from faecal strains, although strains isolated from blood were significantly more often found in certain subclusters, whereas other subclusters contained mainly control strains. Bacteraemic strains possessed P-fimbriae more often, especially strains isolated from patients with $E$. coli in the urine concomitantly with bacteraemia. Equally, no single reaction could separate P-fimbriated from non-P-fimbriated strains. D-Tagatose was fermented more often by the P-fimbriated strains; on the other hand, melibiose and lactose fermentation tests were less often positive. Certain $\mathrm{O}$ serotypes $(\mathrm{O} 1, \mathrm{O} 4$, O6, 07,018 and $\mathrm{O} 25$ ) were more common among bacteraemic isolates than controls. $\mathrm{K}$ serotypes such as $\mathrm{K} 1, \mathrm{~K} 5$ and $\mathrm{K} 52$ were also more frequent among blood isolates. We conclude that a combination of biochemical tests, fimbriation and serotyping might be used to identify potentially pathogenic clusters of $E$. coli.
\end{abstract}

\section{INTRODUCTION}

Escherichia coli is one of the major micro-organisms causing non-obstructive urinary tract infections in children (Winberg et al., 1974) as well as in adults (Jacobson et al., 1985). It is also one of the most common micro-organisms found in blood cultures (McGowan et al., 1979). Bacteraemia caused by $E$. coli is generally associated with a high mortality rate (Weinstein et al., 1983). When the portal of entry is the non-obstructed urinary tract, however, the mortality rate of $E$. coli bacteraemia is lower (Brauner et al., 1985).

The identification of $E$. coli seldom causes problems in the clinical laboratory. Many studies have shown that $E$. coli is a species consisting of phenotypically variable strains (Orskov, 1984).

Abbreviations: PPA, P-fimbriae particle agglutination test; DAC, diagnostic ability coefficient. 
Certain properties of $E$. coli strains are associated with specific virulence attributes e.g. certain $\mathrm{O}$-serotypes are associated with urinary tract infection $(\mathrm{O} 1, \mathrm{O} 2, \mathrm{O} 4, \mathrm{O} 6, \mathrm{O} 7, \mathrm{O} 8, \mathrm{O} 9, \mathrm{O} 11, \mathrm{O} 22$, O25, O62 and O75) (Orskov, 1978), enteropathogenic strains (EPEC), enterotoxinogenic strains (ETEC) or enteroinvasive strains (EIEC) (Orskov, 1984). On the other hand, neonatal septicaemia and meningitis are often associated with capsular serotype K1 (McCracken et al., 1974).

Adhesion of $E$. coli to uroepithelial cells is a virulence attribute of strains causing human urinary tract infections. Most $E$. coli strains causing acute pyelonephritis show mannoseresistant agglutination of human erythrocytes (Källenius \& Möllby, 1979; Green \& Thomas, 1981 ; Hagberg et al., 1981). The adhesion of pyelonephritogenic $E$. coli is, in the majority of cases, mediated by fimbriae with specificity for glycosphingolipids corresponding to antigens of the $\mathbf{P}$ blood group system (Källenius et al., 1981), accordingly named P-fimbriae. The minimal active receptor structure is the $\alpha-\mathrm{D}-\mathrm{Gal} p-(1 \rightarrow 4)-\beta$-D-Gal $p$ disaccharide sequence (Källenius et al., 1980). A high incidence of P-fimbriated $E$. coli is normally found in the urine from children (Källenius et al., 1981) as well as from adults (Jacobson et al., 1985) with the first attack of acute pyelonephritis.

Biotyping appears to be a useful method to identify isolates of $E$. coli (Gargan et al., 1982). By examining a number of biochemical reactions, especially those which have around $50 \%$ positive reactions, a number of profiles are created which allow a precise identification of various strains. However, there seem to be few distinctive biochemical characters associated with virulence although enterotoxinogenic strains, for example, are associated with certain phenotypes (Kühn \& Möllby, 1986). Colonization of the intestinal tract of infants with $E$. coli does not seem to occur at random, and one investigation indicated that certain phenotypes or clones have a greater tendency to establish themselves in the gastrointestinal tract (Kühn et al., 1986).

In order to study the occurrence of $\mathrm{O}$ and $\mathrm{K}$ serotypes and $\mathrm{P}$-fimbriae and to correlate them with biochemical characteristics we have by multivariate analysis investigated $116 \mathrm{E}$. coli strains isolated from blood cultures and compared them with $E$. coli strains isolated from faeces of healthy individuals.

\section{METHODS}

Patients. During a 30 month period (January 1, 1983 to June 30, 1985), 113866 patients were hospitalized at the Karolinska Hospital, Stockholm, Sweden. Blood cultures were taken from 3356 patients and a significant growth was observed in 542 of these. E. coli was found in 104 patients with a total of 116 bacteraemic episodes. The cases were retrospectively evaluated by review of hospital charts: 54 were women, median age 64 years, and 50 were men, median age 63 years (ranges $12-93$ and 4-89 years, respectively). The controls used were $99 \mathrm{E}$. coli strains from faecal swabs obtained from 94 healthy individuals ( 37 women and $57 \mathrm{men}$ ) visiting a health care centre.

Microbiological investigation. Blood cultures were done using a biphasic medium (Bio-Test, Bio-Hospital, Sweden). The agar slant contained brain heart infusion agar (Difco) with $p$-aminobenzoic acid (PABA) and sodium polyanethole sulphonate (SPS). The liquid phase contained meat infusion broth (Oxoid) with penicillinase. About $5 \mathrm{ml}$ blood was injected into each of two vials, one for aerobic and one for anaerobic culture. The blood cultures were subcultured after $2 \mathrm{~d}$ and inspected daily for growth for $7 \mathrm{~d}$.

Biochemical testing. All Gram-negative bacteria from blood isolates were identified by the API 20E system and the accompanying code book. E. coli strains were further analysed with the API 50 CHE system. A conventional lactose test on CLED agar (Oxoid) was done on all strains.

Taxonomic study. The following tests were taken into account for the classification process: conventional lactose fermentation test, API $20 \mathrm{E}$ (first 11 tests) and API 50 CHE tests except for lactose fermentation.

A similarity matrix was established using Gower's generalized coefficient (Gower, 1971), without taking into account negative matching. A dendrogram was then constructed using the UPGMA method (Sneath \& Sokal, 1973). The clusters were determined empirically. The set of most efficient tests for differentiation of the clusters was determined using a method based on Descamps's Diagnostic Ability Coefficient INF (Descamps \& Veron, 1981).

Test for $P$-fimbriation. Briefly, bacteria were grown overnight at $37^{\circ} \mathrm{C}$ on colonization factor antigen (CFA) agar (Evans et al., 1977) and subsequently tested for P-fimbriation using the P-fimbriae specific particle agglutination (PPA) test as described by Svenson et al. (1982). This test is based on the specific agglutination of particles to 
which the minimal P-fimbriae receptor active carbohydrate structure, $\alpha$-D-Galp-(1-4)- $\beta$-D-Galp, is attached (Källenius et al., 1980).

Determination of $O$ antigens. Serotyping was done in plastic microtitre plates according to Lidin-Janson et al. (1977). E. coli strains were tested for the presence of 68 antigens selected because of their occurrence among $E$. coli strains isolated from patients with urinary tract infection. Some strains (designated non-typable) could not be typed with the antisera available.

Determination of $K$ antigen. This was done using agar plates containing antiserum, as described by Kaijser (1977); 23 different antisera were used. Some strains (designated non-typable) could not be typed with the antisera available.

Statistical methods. Fisher's exact two-tailed test and the Chi square test were used (Sokal \& Rohlf, 1981).

\section{RESULTS}

\section{Patients}

A total of $116 \mathrm{E}$. coli strains were isolated from 104 patients. There was an equal distribution among men and women. The majory (96) of the patients had only one bacteraemic episode, whereas seven patients had two bacteraemic episodes during the observation time. Four of these reinfections occurred within 3 months, the others after 8,23 and 27 months. One patient had three bacteraemic episodes at 2 and 3 month intervals. Three patients had two different $E$. coli strains in the same blood culture. Five more patients had mixed infections with other bacteria, two with other Enterobacteriaeceae and the other three with Streptococcus spp. non-pyogenes.

\section{Biochemical markers}

The analysis of the biochemical markers is given in Fig. 1. A primary cutting at a similarity coefficient of 0.8 allowed us to define six main clusters, numbered from $A$ to $F$ on the Figure. Cluster $\mathrm{C}$ could be subdivided into three subclusters $(\mathrm{Cl}, \mathrm{C} 2$ and $\mathrm{C} 3)$ at a similarity coefficient of 0.85 and $\mathrm{C} 2$ and $\mathrm{C} 3$ into two further clusters each ( $\mathrm{C} 2 \mathrm{a}, \mathrm{C} 2 \mathrm{~b}$ and $\mathrm{C} 3 \mathrm{a}, \mathrm{C} 3 \mathrm{~b}$ respectively) at 0.88 similarity. Cluster $\mathrm{D}$ was subdivided into three clusters at 0.86 similarity and D1 into two clusters (Dla and D1b) at 0.89 similarity. Cluster $\mathrm{E}$ was divided into two subclusters (E1 and E2) at 0.87 similarity. Finally, cluster $F$ could be subdivided into two clusters (F1 and $F 2$ ) at 0.82 similarity, and F2 into two more subclusters (F2a and F2b) at 0.85 similarity. A triangle representation has been drawn to show the relations between these clusters (Fig. 1).

The tests were ranked by using the decreasing diagnostic ability coefficient (DAC) (Descamps \& Veron, 1981). The overall most discriminating tests were D-tagatose $(0 \cdot 89)$, saccharose $(0 \cdot 75)$, salicin $(0 \cdot 70)$ and sorbose $(0 \cdot 69)$. Among these tests, a set was chosen so that each pair of clusters was separated by at least one test at a DAC greater than or equal to 0.75 , except for cluster $\mathrm{C} 2 \mathrm{~b}$ for 5 -oxogluconate $(\mathrm{DAC}=0.66$ ). Table 1 shows the percentage of positive reactions for the different clusters for the 11 tests selected. The percentages of positive reactions among bacteraemic and control strains were also calculated although no single test had a DAC high enough to permit discrimination.

\section{Occurrence of P-fimbriated E. coli}

Almost half the strains isolated in blood cultures were P-fimbriated (47\%). Four strains could not be evaluated with the PPA test. Strains from bacteraemic patients showed a significantly higher incidence of P-fimbriation (53/112) than E. coli isolated from the faecal flora in healthy controls $(10 / 98$, one strain was non-typable, $P<0 \cdot 001)$. Among the bacteraemic patients there was a higher incidence of $P$-fimbriated strains in patients who also had a positive urine culture $(35 / 58,60 \%)$, than in patients with negative urine culture or where no urine culture was taken $(18 / 54,33 \%, P<0.01)$.

In cluster B all seven strains came from patients with bacteraemia. All but one were Pfimbriated and six of them belonged to the K 1 serotype. Of three O16 serotypes in the material, all were found in cluster B. In cluster D3 all seven strains also originated from patients with bacteraemia and all were P-fimbriated.

No single biochemical test could distinguish between P-fimbriated and non-P-fimbriated strains. D-Tagatose was fermented in $46 / 51(90 \%)$ of the P-fimbriated strains, but only in $37 / 55$ 


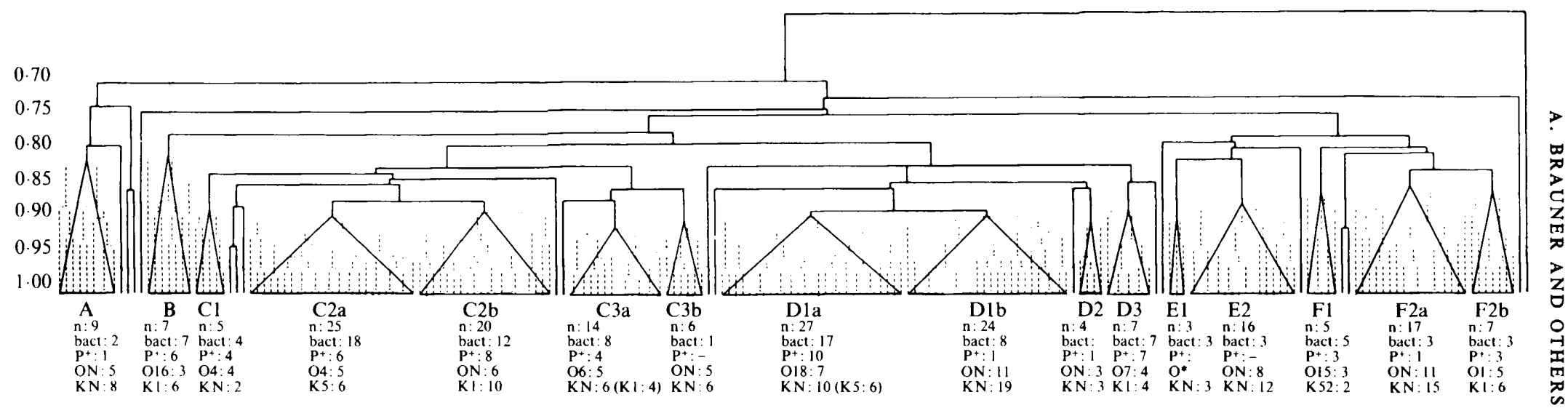

Fig. 1. Dendrogram showing clustering of 225 strains of $E$. coli based on the results of 61 biochemical tests. Abbreviations: $\mathrm{n}$, No. of isolates in a cluster; bact, number of isolates from blood culture; $\mathrm{P}^{+}$, number of $\mathrm{P}$-fimbriated strains; $\mathrm{O}, \mathrm{K}$, predominating serotype in a cluster. When non-typable ( $\mathrm{N}$ ) strains are in a majority, but a typable serotype is of interest, this figure is given as well. ${ }^{*}$ No dominating $\mathrm{O}$-serotype. 
Table 1. Biochemical tests on strains in different clusters

The values given are the percentage of positive reactions for 11 selected tests on isolates in the clusters shown in Fig. 1. Sixteen bacteraemic isolates and three control strains could not be grouped into any cluster and were therefore excluded from this Table.

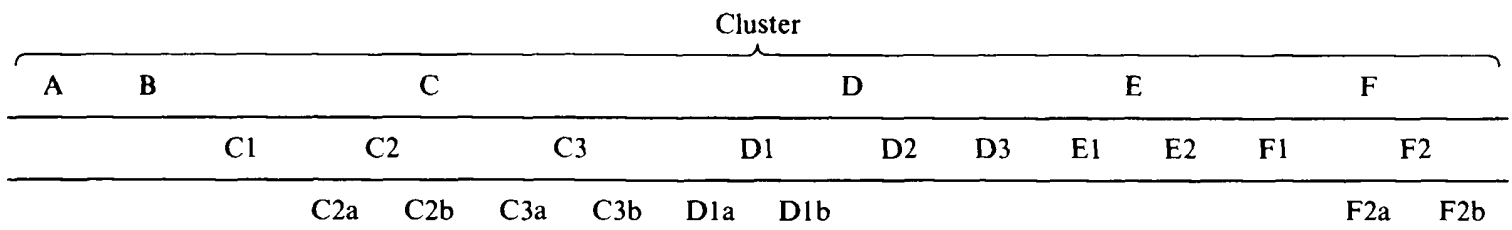

$\begin{array}{llllll}\text { Total no. of strains } & \ldots & 9 & 7 & 5 & 25 \\ \text { Bacteraemic strains } & \ldots & 2 & 7 & 4 & 18 \\ \text { Control strains } & \ldots & 7 & 0 & 1 & 7 \\ \text { Adonitol } & & 100 & 0 & 0 & 0 \\ \text { Sorbose } & & 0 & 86 & 100 & 100 \\ \text { Aesculin } & & 67 & 43 & 100 & 1 \\ \text { Salicin } & & 67 & 0 & 100 & 1 \\ \text { Sucrose } & 11 & 14 & 20 & 4 \\ \text { Raffinose } & 33 & 0 & 0 & 8 \\ \text { D-Tagatose } & 0 & 100 & 100 & 96 \\ \text { 5-Oxogluconate } & 22 & 86 & 40 & 80 \\ \text { Lysine decarboxylase } & 56 & 100 & 100 & 92 \\ \text { Ornithine decarboxylase } & 11 & 100 & 100 & 1 \\ \text { Lactose } & 100 & 0 & 0 & 100\end{array}$

$\begin{array}{llllll}25 & 20 & 14 & 6 & 27 & 24 \\ 18 & 12 & 8 & 1 & 17 & 8 \\ 7 & 8 & 6 & 5 & 10 & 16 \\ 0 & 0 & 0 & 0 & 0 & 0 \\ 100 & 100 & 100 & 17 & 93 & 100 \\ 100 & 45 & 100 & 100 & 19 & 0 \\ 100 & 0 & 100 & 100 & 0 & 4 \\ 4 & 0 & 100 & 100 & 100 & 100 \\ 8 & 0 & 86 & 100 & 96 & 100 \\ 96 & 95 & 100 & 0 & 100 & 4 \\ 80 & 85 & 57 & 100 & 67 & 58 \\ 92 & 80 & 86 & 67 & 85 & 96 \\ 100 & 95 & 100 & 100 & 93 & 54 \\ 100 & 100 & 100 & 83 & 100 & 96\end{array}$

$\begin{array}{ll}4 & 7 \\ 0 & 7 \\ 4 & 0 \\ 0 & 0 \\ 0 & 100 \\ 25 & 0 \\ 0 & 0 \\ 100 & 100 \\ 75 & 57 \\ 0 & 100 \\ 0 & 100 \\ 100 & 0 \\ 100 & 0 \\ 100 & 86\end{array}$

$\begin{array}{lllll}7 & 3 & 16 & 5 & 17 \\ 7 & 3 & 3 & 5 & 3 \\ 0 & 0 & 13 & 0 & 14 \\ 0 & 0 & 0 & 0 & 0 \\ 100 & 33 & 0 & 100 & 0 \\ 0 & 100 & 100 & 0 & 6 \\ 0 & 33 & 81 & 0 & 6 \\ 100 & 0 & 0 & 0 & 0 \\ 57 & 100 & 13 & 0 & 0 \\ 100 & 0 & 0 & 0 & 0 \\ 100 & 33 & 25 & 60 & 18 \\ 0 & 100 & 94 & 20 & 100 \\ 0 & 100 & 6 & 0 & 24 \\ 86 & 67 & 100 & 100 & 100\end{array}$

196

100

$\begin{array}{lllllll}100 & 86 & 67 & 100 & 100 & 100 & 100\end{array}$ Total 
$(67 \%)$ of the non-P-fimbriated strains $(P<0.01)$. On the other hand, melibiose and lactose were less often fermented by the P-fimbriated strains $(41 / 51,80 \%$ and $39 / 51,77 \%)$ than by the non-Pfimbriated strains $(54 / 55,98 \%$ and $53 / 55,96 \%, P<0.01$ in both cases).

\section{E. coli serotypes}

The distribution of $\mathrm{O}$ and $\mathrm{K}$ antigen serotypes of the $E$. coli strains from bacteraemic patients is shown in Table 2 . Ninety of the $116(78 \%) E$. coli strains isolated from patients with bacteraemia were O-typable. E. coli serotype $\mathrm{O} 18$ was most frequently found ( $16 \%$ of the typable isolates). E. coli serotype $\mathrm{O} 4$ was found in $12 \%$ of the isolates and serotypes, $\mathrm{O} 1, \mathrm{O} 6, \mathrm{O} 7$ and $\mathrm{O} 25$ occurred in $8 \%$ each. With the available $\mathrm{K}$ antisera $70 / 116(60 \%)$ E. coli strains were typable. K1 was the most frequently found $\mathrm{K}$ serotype $(35 / 70,50 \%$ ) of the $\mathrm{K}$-typable strains. $\mathrm{K} 5$ was found in $17 \%$ and $\mathrm{K} 52$ in $7 \%$ of the typable bacteraemic $E$. coli isolates.

The serotypes of $E$. coli strains from bacteraemic patients were compared to those isolated from faeces in healthy controls. Among the control strains, $57 \%$ were O-non-typable and $62 \%$ $\mathrm{K}$-non-typable with the available antisera. The main typable serotypes were $\mathrm{O} 1, \mathrm{O} 2$ and $\mathrm{O} 75$ with seven, six and four strains respectively in each group, and K1 and K5 with 22 and six strains in each group. Strains from patients with bacteraemia showed a significantly higher incidence (53/116) of certain $\mathrm{O}$ serotypes $(\mathrm{O} 1, \mathrm{O} 4, \mathrm{O} 6, \mathrm{O} 7, \mathrm{O} 18$ and $\mathrm{O} 25)$ than did the strains from the controls $(15 / 99, P<0.001 \mathrm{Chi}$ square test). E. coli from bacteraemic patients also had a significantly higher incidence $(52 / 116)$ of certain $\mathrm{K}$ antigens $(\mathrm{K} 1, \mathrm{~K} 5$ and $\mathrm{K} 52)$ than in isolates from controls $(28 / 99, P<0 \cdot 01$, Chi square test).

The analysis of the clusters revealed a tendency to unequal distribution among the serotypes. Seven of eight strains in cluster B belonged to serotype $\mathrm{K} 1$, which is significantly higher than in the rest of the bacteraemic strains $(P<0.002$, Fischer's exact test $)$. The O-serotypes showed a similar tendency to unequal distribution. The numbers in the different clusters were, however, too small to permit any further conclusions.

\section{DISCUSSION}

Analysis of biochemical data indicated that certain clusters were associated with pathogenic properties. Statistical analysis of the numbers of bacterial and control strains among the various subclusters showed a highly significant deviation from random distribution $(P<0.001$, Chi square test).

In cluster D3, where all seven isolates were from patients with bacteraemia, four strains belonged to the $\mathrm{K} 1$ serotype and the remaining strains were $\mathrm{K}$-non-typable. Of four $\mathrm{O} 7$ serotypes in the whole material, all were found in cluster D3; the remaining strains in that cluster were Onon-typable. Two more clusters, namely $E 1$ and Fl, containing isolates from three and five patients respectively, also had strains only from patients with bacteraemia. However, in one cluster, D2, all four strains originated from healthy individuals. Cluster E2 with 16 strains had only three strains originating from patients with bacteraemia. The same relationship was found in cluster F2a, where 3/17 strains originated from bacteraemic patients.

The incidence of P-fimbriated $E$. coli isolated from patients with bacteraemia was $47 \%$. In an earlier study (Brauner et al., 1985) $63 \%$ of $E$. coli causing bacteraemia were P-fimbriated. In the present study, a high percentage, $47 / 112(42 \%$ ) (four strains non-typable with the available PPA test) of the patients had compromising diseases, such as malignancies; acute colitis, cholecystitis or pancreatitis; debilitating drug abuse or chronic corticosteroid treatment. This distribution among the patients was found in our earlier study and can probably explain the differences in Pfimbriation of the blood isolates. In both studies the highest incidence of P-fimbriated strains was found in bacteraemic patients who previously had been apparently healthy and in whom the portal of entry was the urinary tract.

$\mathrm{K}$ antigens generally associated with urinary tract infection $(\mathrm{K} 1, \mathrm{~K} 2, \mathrm{~K} 3, \mathrm{~K} 12, \mathrm{~K} 13, \mathrm{~K} 52$, K53 and K54) (Kaijser, 1973; Kaijser et al., 1977; Svanborg-Eden et al., 1978) were found in $48 / 70 \mathrm{~K}$-typable strains $(69 \%)$. Of 90 O-groupable $E$. coli strains 58 belonged to O serotypes associated with urinary tract infection (Orskov, 1978). These E. coli strains revealed a 
Table 2. $O$ and $K$ serotypes in E. coli strains from blood cultures

(a) P-fimbriated strains

Four P-fimbriae non-typable strains have been included.

O-Antigenic type

\begin{tabular}{|c|c|c|c|c|c|c|c|c|c|c|c|c|c|c|c|c|c|c|c|c|c|c|c|c|c|}
\hline $\begin{array}{l}\text { K Antigenic } \\
\text { type }\end{array}$ & 1 & 2 & 4 & 6 & 7 & 8 & 10 & 11 & 15 & 16 & 17 & 18 & 22 & 25 & 75 & 83 & 101 & 119 & 120 & $\begin{array}{l}22 \\
83\end{array}$ & $\begin{array}{l}19 \\
23\end{array}$ & $\begin{array}{l}5 \\
23 \\
42 \\
59\end{array}$ & $\begin{array}{c}\text { Total } \\
\text { O- } \\
\text { typable } \\
\text { strains }\end{array}$ & $\begin{array}{c}\text { Total } \\
\text { non-O- } \\
\text { typable } \\
\text { strains }\end{array}$ & Total \\
\hline K1 & 4 & 1 & - & - & 1 & - & - & - & - & 3 & - & 1 & - & 1 & - & - & .. & - & - & -- & - & - & 11 & 6 & 17 \\
\hline K2 & - & - & - & - & - & - & - & - & - & - & - & - & - & - & $\ldots$ & - & - & - & - & - & - & - & - & 1 & 1 \\
\hline K3 & - & - & - & - & - & - & - & - & - & - & - & .- & $\ldots$ & - & - & - & -- & - & - & - & - & - & - & - & - \\
\hline K5 & - & 1 & - & 1 & - & - & - & - & - & - & - & 5 & - & 2 & - & - & .- & - & - & - & - & - & 9 & - & 9 \\
\hline K7 & - & - & - & - & - & - & - & - & .. & $\ldots$ & - & - & - & - & - & $\ldots$ & - & - & - & - & - & - & - & - & - \\
\hline K10 & - & - & - & - & - & - & - & . & - & - & - & - & - & - & - & - & - & - & . & - & - & - & - & - & - \\
\hline $\mathrm{K} 12$ & - & - & 2 & - & - & - & - & - & - & - & - & - & - & - & - & - & - & - & - & - & - & - & 2 & - & 2 \\
\hline K 13 & - & - & - & 1 & - & - & - & - & - & - & - & - & - & - & - & - & - & $\ldots$ & - & - & -. & - & 1 & - & 1 \\
\hline K 16 & - & - & - & - & - & - & - & - & .. & - & - & 1 & - & - & - & - & - & - & - & & - & - & 1 & - & 1 \\
\hline K 22 & - & - & - & - & - & - & - & - & - & - & - & - & - & -. & - & - & - & - & - & - & - & - & - & - & - \\
\hline K 24 & - & - & - & - & - & - & - & - & - & - & - & - & -. & - & - & - & - & - & - & - & - & - & - & -- & - \\
\hline K51 & - & - & - & - & - & - & - & - & - & - & - & - & - & - & - & - & - & - & - & - & - & - & - & - & - \\
\hline K52 & - & - & 3 & - & - & - & - & - & 2 & - & - & - & - & - & - & - & - & - & - & - & $\ldots$ & - & 5 & $\ldots$ & 5 \\
\hline K53 & - & - & - & - & $\ldots$ & - & -. & - & - & .. & - & - & - & & - & - & - & - & - & - & - & - & .. & - & - \\
\hline K95 & - & - & - & - & - & - & - & - & - & - & - & - & - & - & - & - & - & - & - & $\cdots$ & - & - & - & ... & - \\
\hline $\begin{array}{l}\text { Total, K- } \\
\text { typable } \\
\text { strains }\end{array}$ & 4 & 2 & 5 & 2 & 1 & - & - & - & 2 & 3 & - & 7 & - & 3 & - & - & - & - & - & - & - & - & 29 & 7 & 36 \\
\hline $\begin{array}{l}\text { Non-K- } \\
\text { typable }\end{array}$ & & & & & & & & & & & & & & & & & & & & & & & & & \\
\hline strains & - & 1 & 3 & 3 & 3 & - & & 1 & - & - & - & 2 & - & - & 2 & - & - & - & .. & 2 & - & - & 17 & - & 17 \\
\hline Total & 4 & 3 & 8 & 5 & 4 & - & - & 1 & 2 & 3 & - & 9 & - & 3 & 2 & - & - & - & $\ldots$ & 2 & - & - & 46 & 7 & 53 \\
\hline
\end{tabular}




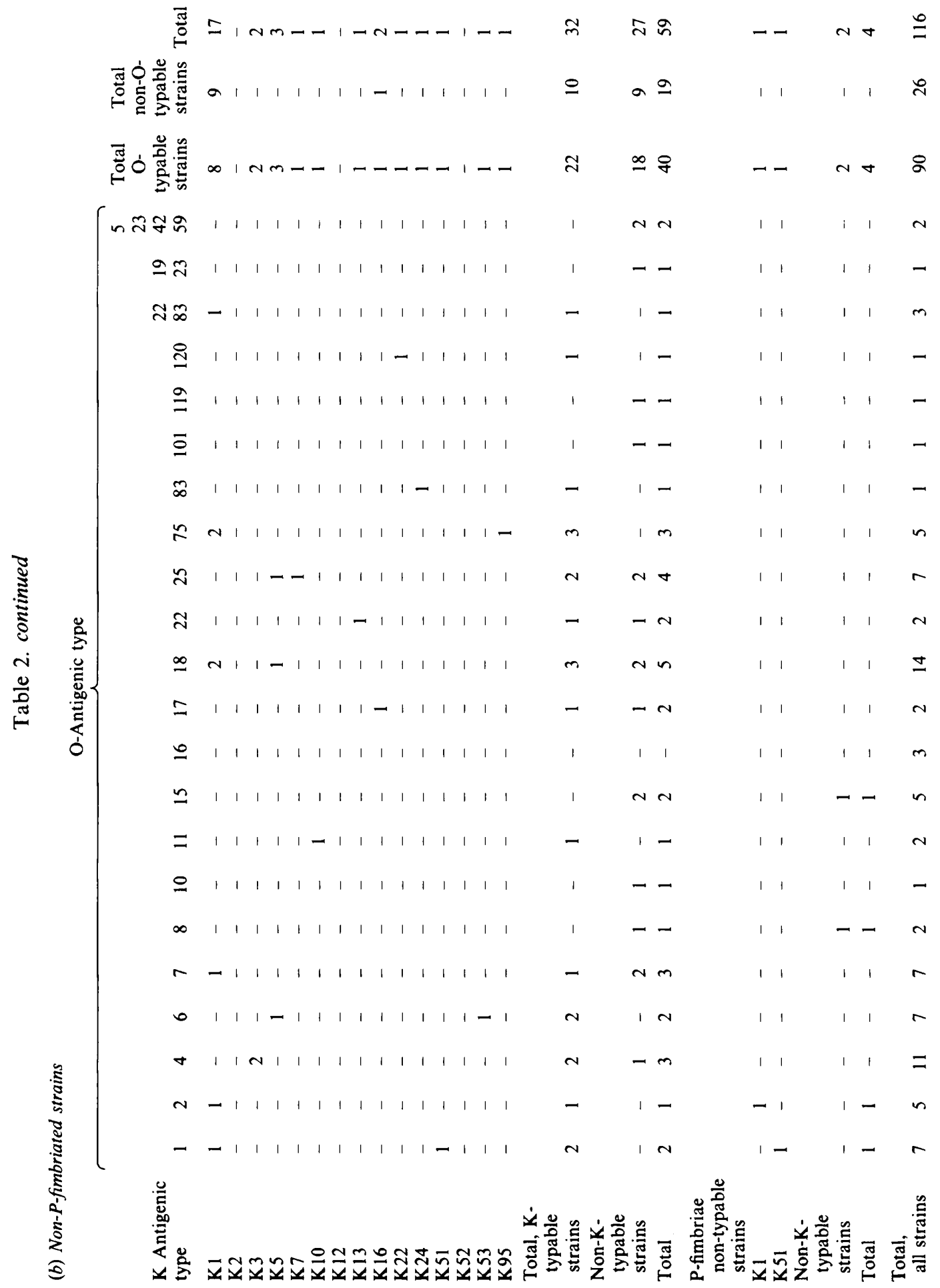


significantly higher incidence (32/55, three strains non-typable with the PPA test) of Pfimbriation than strains belonging to other serotypes (21/57, one strain non-typable with the PPA test, $P<0.05$ Fisher's exact test). Orskov \& Orskov (1975) showed that more than half of the O-groupable E. coli isolates from blood cultures were $\mathrm{O} 2, \mathrm{O} 4, \mathrm{O} 6$ or $\mathrm{O} 75$. Among E. coli strains isolated at the Karolinska Hospital only $31 \%$ belonged to any of these groups. This low incidence might be due to the large number of patients with compromising diseases which enable even $E$. coli strains with a normally low virulence to become pathogenic.

Certain clones of a limited number of $E$. coli strains (Väisinen-Rhen et al., 1984) have been shown to be associated with pyelonephritis. These strains possess certain homogeneous characteristics such as P-fimbriae and special $\mathrm{O}$ and $\mathrm{K}$ antigens. Tullus et al. (1984) reported epidemic outbreaks of first-time pyelonephritis and bacteraemia caused by particular $E$. coli clones in children previously being cared for in a particular neonatal ward. Neonates and staff of this ward showed a high incidence of the same $E$. coli strain in their faecal flora, indicating nosocomial spread. Pyelonephritis and septicaemia induced by $E$. coli has also been reported from an infant nursery (Sweet \& Wolinsky, 1964).

In this study, we had few indications of nosocomial spread of $E$. coli strains. Only two patients, both heavily compromised, and treated at the oncological department, had strains belonging to the same biochemical cluster.

Other methods based on characterization of outer membrane proteins and plasmid content have been used (Achtman et al., 1983; Achtman \& Pluschke, 1986) in differentiating E. coli strains. These methods, although effective, seem less suitable for screening large numbers of strains.

We conclude that $E$. coli strains causing bacteraemia were P-fimbriated and that a higher percentage belonged to certain $\mathrm{O}$ and $\mathrm{K}$ serotypes compared with the control strains. We also found that a few biochemical markers were associated with bacteraemia and P-fimbriation. A combination of biochemical markers, serotypes and fimbriation might therefore be helpful in the detection of potentially virulent $E$. coli clones. However, the clones found in this study had properties characteristic of our hospital. At other times and in other hospitals the patterns might vary.

This study was supported by grants $19 X-06867$ from the Swedish Medical Research Council and the Tore Nilson Foundation for Medical Research and Funds from the Karolinska Institute. We thank Anna-Lisa Belin and Annette Olin for skilful technical assistance.

\section{REFERENCES}

Achtman, M. \& Pluschke, G. (1986). Clonal analysis of descent and virulence among selected Escherichia coli. Annual Review of Microbiology 40, 185-210.

Achtman, M., Mercer, A., Kusecek, B., Pohl, A., Heuzenroeder, M., Aaronson, W., Sutton, A. \& SILVER, R. P. (1983). Six widespread bacterial clones among Escherichia coli $\mathrm{K} 1$ isolates. Infection and Immunity 39, 315-335.

BRAUNER, A., LEISSNER, M., WRETLIND, B., JULANDER, I., Svensson, S. B. \& Källenius, G. (1985). Occurrence of P-fimbriated Escherichia coli in patients with bacteremia. European Journal of Clinical Microbiology, 4, 566-569.

DesCAMPS, P. \& VeRoN, M. (1981). Une methode de choix des caractères d'identification basée sur le théorème de Bayes et la mesure de l'information. Annales de Microbiologie 132B, 157-170.

Evans, D. G., Evans, D. J. \& TuOA, W. (1977). Hemagglutination of human group A erythrocytes by enterotoxinogenic Escherichia coli isolated from adults with diarrhea: correlation with colonization factor. Infection and Immunity 18, 330-337.
Gargan, R., Brumfitt, W. \& Hamilton-Miller, J. M. T. (1982). A concise biotyping system for differentiating strains of Escherichia coli. Journal of Clinical Pathology 35, 1366-1369.

Gower, J. C. (1971). A general coefficient of similarity and some of its properties. Biometrics 27, 857-874.

Green, C. P. \& Thomas, V. L. (1981). Hemagglutination of human type $O$ erythrocytes, hemolysin production, and serogrouping of Escherichia coli isolates from patients with acute pyelonephritis, cystitis, and asymptomatic bacteriuria. Infection and Immunity 31, 309-315.

HAGBerg, L., JODAL, U., KORHONEN, T. K., LIDINJanson, G., Lindberg, U. \& SVANborg-Edén, C. (1981). Adhesion, hemagglutination, and virulence of Escherichia coli, causing urinary tract infections. Infection and Immunity 31, 564-570.

JaCOBSON, S., Källenius, G., Lins, L. E. \& Svenson, S. B. (1985). P-fimbriated Escherichia coli in adults with acute pyelonephritis. Journal of Infectious Diseases 152, 426-427. 
KAIJSER, B. (1973). Immunology of Escherichia coli: K antigen and its relation to urinary-tract infection. Journal of Infectious Diseases 127, 670-677.

KAIJSER, B. (1977). A simple method for typing of acidic polysaccharide $\mathrm{K}$ antigens of Escherichia coli. FEMS Microbiology Letters 1, 285-288.

KaijSER, B., Hanson, L. A., Jodal, U., Lidin-JANSON, G. \& RobBins, J. B. (1977). Frequency of E. coli K antigens in urinary-tract infections in children. Lancet i, 663-664.

KäLleniUS, G. \& Möllby, R. (1979). Adhesion of Escherichia coli to human periurethral cells correlated to mannose-resistant agglutination of human erythrocytes. FEMS Microbiology Letters 5, 295299.

Källenius, G., Möllby, R., Svenson, S. B., WiNBERG, J. \& HULTBERG, H. (1980). Identification of a carbohydrate receptor recognized by uropathogenic Escherichia coli. Infection 8, supplement 3, S288S293.

Källenius, G., Möllby, R., Svenson, S. B., Helin, I., Hultberg, H., Cedergren, B. \& Winberg, J. (1981). Occurrence of P-fimbriated Escherichia coli in urinary tract infections. Lancet ii, 1369-1372.

KüHN, I. \& MöllbY, R. (1986). Phenotypic variations among enterotoxinogenic O-groups of $E$. coli from various human populations. Medical Microbiology and Immunology 175, 15-26.

KüHN, I., Tullus, K. \& Möllby, R. (1986). Colonization and persistence of Escherichia coli phenotypes in the intestines of children 0 to 18 months of age. Infection 14, 7-12.

Lidin-Janson, G., Falsen, E., Jodal, U., KaiJser, B. \& LinCOLN, K. (1977). Characteristics of antibioticresistant Escherichia coli in the rectum of healthy school-children. Journal of Medical Microbiology 10, 299-308

McCracken, G. H., JR, SarfF, L. D., Glode, M. P., Mize, S. G., Schiffer, M. S. Robbins, J. B., Gotschlich, E. C., ÖrssKov, I. \& ÖrsKov, F. (1974). Relation between Escherichia coli $\mathrm{Kl}$ capsular polysaccharide antigen and clinical outcome in neonatal meningitis. Lancet ii, 246-250.

McGowan, J. E., JR, Barnes, M. W. \& Finland, M. (1975). Bacteremia at Boston City Hospital: occurrence and mortality during 12 selected years (19351972), with special reference to hospital acquired cases. Journal of Infectious Diseases 132, 316-335.

ORSKOV, F. (1978). Virulence factors of the bacterial cell surface. Journal of Infectious Diseases 137, 630 633.

OrSKov, F. (1984). Genus Escherichia. In Bergey's Manual of Systematic Bacteriology, 9th edn, vol. 1 . Edited by N. R. Krieg. Baltimore: Williams \& Wilkins.

OrsKov, F. \& Orskov, I. (1975). Escherichia coli O:H serotypes isolated from human blood. Acta pathologica et microbiologica scandinavica B83, 595-600.

SNeath, P. H. A. \& Sokal, R. R. (1973). Numerical Taxonomy. San Francisco: W. H. Freeman.

SoKal, R. R. \& RohlF, F. J. (1981). The Principal and Practice of Statistics in Biological Research, pp. 738 743. San Francisco: W. H. Freeman.

Svanborg-Edén, C. ERIKsson, B., Hanson, L. Å., JODAL, U., KAIJSER, B., LIDIN-JANSON, G., LINDBERG, U. \& OlLING, S. (1978). Adhesion to normal human uroepithelial cells from children with various forms of urinary tract infection. Journal of Pediatrics 93, 398-403.

Svenson, S. B., Källenius, G., Möllby, R., HultBERG, H.\& WINBERG, J. (1982). Rapid identification of P-fimbriated Escherichia coli by a receptorspecific particle agglutination test. Infection 10, 209214.

SWEET, A. Y. \& WolinSKy, E. (1964). An outbreak of urinary tract and other infections due to $E$. coli. Pediatrics 33, 865-871.

Tullus, K., Hörlin, K., Svenson, S. B. \& Källenius, G. (1984). Epidemic outbreaks of acute pyelonephritis caused by nosocomial spread of P-fimbriated $E$. coli. Journal of Infectious Diseases 150, 728-736.

Weinstein, M., MurPhy, J., Reller, L. \& LiChtenSTEIN, K. (1983). The clinical significance of positive blood cultures: a comprehensive analysis of 500 episodes of bacteremia and fungemia in adults. II. Clinical observations, with special references to factors influencing prognosis. Reviews of Infectious Diseases 5, 54-70.

Winberg, J., ANDERSEN, H. J., BergStröm, T., JACOBSON, B., LARSSON, H. \& LiNCOLN, K. (1974). Epidemiology of symptomatic urinary tract infection in childhood. Acta paediatrica scandinavica, supplement 252, 1-20.

VÄISENEN-RHEN, V., Elo, J., VÄISÄNEN, E., SiItonen, A., ORSKOV, I., ORSKOV, F., SVENSON, S. B., MÄKELÄ, H. \& KoRHONEN, T. K. (1984). Pfimbriated clones among uropathogenic Escherichia coli strains. Infection and Immunity 43, 149-155. 